\title{
Cuidado domiciliar: em busca da autonomia do indivíduo e da família - na perspectiva da área pública
}

\author{
Home care: searching for individual and family's autonomy \\ in the public scope
}

M aria Ribeiro Lacerda $^{1}$

\footnotetext{
${ }^{1}$ Departamento de Enfermagem, Setor de Ciências da Saúde, UniversidadeFederal do Paraná. Rua Padre Camargo 280/80 andar, Bairro Alto. 86410-030 Curitiba PR.

lacerda@milenio.com.br
}

Abstract The objective of thi sessay is to reflect on thepossibility of searching for individual and family's autonomy in public health services through health professionals, mainly nurses in the development of home care. Some aspects related to the organization and health professionals' education must be considered in order to perform home care in health systems, mainly in the public service scope. Effective home care must watch individuals and their families in their context, visualizing and considering their social environment, their insertions, their homes, their habits and relationships, and anything or any situation that are part of their existence in the world. Autonomy - for individuals as well as their families to be able to carry out home care during an illness - is the possibility to deliver care supported by thehealth system, with professionals teaching, guiding and giving follow up, mainly a sensitive and technically-scientifically competent nurse to set up caring goals attending health reality - lived disease.

Key words N ursing, $\mathrm{H}$ ome care delivery, $\mathrm{H}$ ealth home care
Resumo Este texto éum ensaio com o objetivo de refletir sobre a possibilidade da busca da autonomia do indivíduo e da família nos serviços públicos de saúde, através da ação dos profissionais de saúdee, principalmente, da presença da enfermeira no desenvolvimento do cuidado domiciliar. Para realizar o cuidado domiciliar nos sistemas de saúde, principalmente na perspectiva do serviço público, devem ser considerados al guns aspectos referentes à organização e à formação dos profissionais de saúde. 0 sucesso do cuidado domiciliar está em olhar o indivíduo e sua família em seu contexto, visualizando e considerando seu meio social, suas inserções, seu local de moradia, seus hábitos e relações equalquer outra coi sa ou situação que façam parte de seu existir e estar no mundo. Autonomia, para os indivíduos e familiares terem condi ções para desenvolverem o cuidado no domićlio numa situação de adoecimento, éa possibilidade de estar capacitado a realizar o cuidado com ajuda do sistema de saúde, com profissionais que ensinem, orientem e acompanhem e principalmente com uma enfermeira que tenha sensibilidade ecapacidade técnica-científica para estabelecer metas decuidado factíveisà realidade desaúdedoença vivenciada.

Palavras-chave Enfermagem, Assistência domiciliar, Cuidados domiciliares de saúde 
O objetivo deste texto érefletir sobre a possibilidade da busca da autonomia do indivíduo e da família nos serviços públicos de saúde, através da ação dos profissionais de saúde e, principalmente, da presença da enfermeira no desenvolvimento do cuidado domiciliar.

Considero o cuidado a prática genética da enfermagem, que perpassa toda a dimensão sociopolítica denossa prática profissional edemanda que, acima de quaisquer interesses e momentos pelos quais passam nossa categoria profissional e a sociedade, seja nossa bandeira primeira e nossa força de organização e atuação ${ }^{1}$. Portanto, o cuidado é um processo delegado pelo usuário, logo uma concessão, em que é estabelecida uma relação de direitos e deveres entre os sujeitos desta ação, o cuidado, possibilitando uma libertação do usuário econdições necessárias para a sua autonomia e poder viver a vida.

O cuidado domiciliar pode ser uma oportunidade significativa para que a autonomia do indivíduo e da família concretize- se, já queo cuidado no domicílio do usuário, paciente/clientee família é uma ação e atitude, pois, mais do que um fazer, é um momento em que a enfermeira está vivenciando com o indivíduo e a família situações de saúde-doença, em seu locus dehabitação, de relações e de significado de vida.

Experienciar o cuidado domiciliar na perspectiva de compartilhar com o indivíduo e sua família a busca da autonomia é um desafio e uma meta. D esafio porque, em meio a inúmeras situações de cuidado, ter o objetivo de acompanhá-lo no desenvolvimento de sua busca para o cuidado de si com o mínimo de dependência de outros é muitas vezesum chamamento para descobrir formas e possi bilidades de vivência de uma vida digna e com saúde. É também uma meta porque um dos objetivos de cuidado da enfermeira domiciliar éque o indivíduo e sua família possam capacitar-se para seu próprio cuidado e que isto aconteça nas mais diferenciadas condições de viver.

Assim, a enfermeira tem o papel de facilitadora do processo de ajudar o indivíduo e sua família a se autodeterminarem para o cuidado de si com inúmeras estratégias, incluindo a educação, o advogar, assim como gerenciar o caso do paciente e familiares ${ }^{2}$. Ser educadora no cuidado domiciliar envolve o ensino do cuidado de si do paciente, assim como o ensino do cuidado aos cuidadores familiares do paciente, sendo uma das mais significativas ações atribuídas à enfermeira no domicílio ${ }^{3}$. Ensinar os familiares a cuidar é função primordial da enfermeira domiciliar, respeitando a capacidade, o grau de com- preensão e a possibilidade de ação dos cuidadores familiares.

A enfermagem domiciliar é uma especialidade nas ações de trabal ho da enfermeira que exige conhecimento científico-tecnológico, autonomia, responsabilidade, extrema habilidade no relacionamento interpessoal para trabalhar com os pacientes, familiares e equipe multiprofissional. As bases do trabal ho no domicílio são o paciente, a família, o contexto domiciliar e os cuidadores. A enfermeira que trabalha no domicílio dos indivíduos precisa ter competência e perfil próprios. 0 trabal ho sistematizado é acentuado por comunicação, ética eprofundo respeito humano pela vivência das famílias. É também uma oportunidade única para empreender os melhores cuidados de saúde às pessoas e seus relacionamentos em seu local mais íntimo e privado da existência: o lar.

Entendo o cuidado domiciliar na perspectiva deestender os princípios deintegralidadeda atenção à saúde numa difusão do trabalho da unidade básica de saúde ou da unidade que realiza o Programa de Saúde da Família (PSF), assim, a expectativa do usuário (indivíduo, família e comunidade) é resguardada e sua autonomia incrementada.

Para realizar o cuidado domiciliar nos sistemas de saúde e, principalmente, na perspectiva do serviço público, devem ser considerados alguns aspectos referentes à organização e à formação dos profissionais de saúde.

A organização do serviço está centrada nas metas, na efetividadee eficácia, levando os profissionais a um fazer quantitativo muitas vezes sem considerar a qualidade da ação. São preconizadas as atividades que se traduzem por quantas vezes determinada ação é realizada e quem a realizou. N esta perspectiva, através de experiências na prática, se constata que na visão do sistema gestor deste serviço a qualidade da ação e dos resultados alcançados pouco representa ao planejamento financeiro. Assim o número de vezes que determinado paciente, familiares e seu domićlio receberem visitas ou atendimentos são considerados, sem a necessária avaliação da pertinência do cuidado que foi ou não prestado, ou compartilhado com os indivíduos.

A formação dos profissionais de saúde pouco aponta para as questões de cuidado no domicílio, suas perspectivas, peculiaridades e o perfil necessário para um profissional trabalhar nesta especialidade. 0 domicílio, o indivíduo e sua família devem ser percebidos como integrantes de um contexto que é muito mais do que um espaço 
físico, devendo ser percebido com um significado mais amplo, pois éum conjunto de coisas, eventose seres humanos correlacionados entre si e de certo modo, cujas entidades representam caráter particular einterferente mútuo e simultâne ${ }^{3}$. É preciso considerar que a casa e seus integrantes têm diferentes realidades, culturas, valores ecrenças euma totalidade emultidimensionalidadeinerentes.

0 contexto familiar engloba questões sociais, econômicas, culturais e relacionais que adquirem uma perspectiva especial, a qual deveser observada pela enfermeira ao realizar o cuidado domiciliar. É necessário atentar aos padrões culturais deste indivíduo, família e comunidade, respeitando suas tradições, hábitos, sentimentos e necessidades, a fim de enaltecer a humanização e a autonomia dos envolvidos no cuidar. 0 sucesso do cuidado domiciliar está em olhar o indivíduo esua família em seu contexto, visualizando e considerando seu meio social, suas inserções, seu local de moradia, seus hábitos e relações e qualquer outra coisa ou situação que façam parte de seu existir e estar no mundo.

Compactuo com K lock et al. ${ }^{4}$, pois o cuidado domiciliar envolvea família esua vida doméstica e a inserção na dinâmica política e econômica da sociedade como um todo, reforçando os laços sociais, as redes de solidariedade de cada comunidade.

Outro aspecto importante a considerar é o cuidador familiar. No cuidado, é importante saber quem cuida do doente. Esta pessoa o faz por livre escolha ou porque as circunstâncias assim 0 determinaram? Isto tem como consequência a possibilidade de busca da autonomia ou não. A idade ea escolaridade, assim como tempo de cuidado, são importantes aspectos a serem observados pela enfermeira e equipe de saúde ao realizarem o cuidado domiciliar. É necessário que a enfermeira determinejunto ao cuidador quais ações vai realizar para cuidar? Qual a periodicidade de fornecimento de orientações para cuidar? Quem vai orientar, profissionais de saúde ou amigos e vizinhos? Como o fará? Explicará eacompanhará supervisionando as ações de cuidado?

Portanto, a realização do cuidado domiciliar na rede pública de saúde nos leva a indagar sobre al guns aspectos significativos como: estamos capacitando os usuários - pacientes e família - a se cuidarem? Estamos ensinando a família a realizar procedimentos complexos que fazem parte do arcabouço de conhecimento científico-tecnológico de nossa profissão, como tratamento de feridas, uso de cateteres e sonda, limpeza de vias aé reas e outros, quando sabemos que são cuidados essenciais de reparação, mas também de manutenção da vida que exigem conhecimentos acurados para sua execução? Sabemos que, na maior parte da população, quando os indivíduos e familiares vivenciam estas situações de cuidados complexos 24 horas por dia, não há nos serviços públicos profissionais da enfermagem edesaúde, assim como estrutura suficiente para fazê-los. Quem os fará? A família cuidadora assume este papel sobre os auspícios do sistema de saúde, isto é, conquista de autonomia ou de abandono?

Autonomia, para os indivíduos e familiares terem condições para desenvolverem o cuidado no domicílio numa situação de adoecimento, éa possi bilidade de estar capacitado a realizar o cuidado com ajuda do sistema de saúde, com profissionais que ensinem, orientem eacompanhem e principalmentecom uma enfermeira quetenha sensibilidade e capacidade técnica-científica para estabelecer metas de cuidado factíveisà realidade de saúde- doença vivenciada. A enfermeira deve almejar devolver àfamíliaeao indivíduo sua condição plena de gerenciamento de uma vida digna. É possibilitar a capacidade de autogoverno, que permite a escolha de forma racional sobre base de apreciação pessoal às futuras possibilidades, avaliadas em função do próprio sistema de valores, sendo um livrearbítrio. 0 indivíduo e sua família são senhores de suas escolhas, mas tendo as condições materiais e emocionais para fazêlas, pois adquirem competências para tanto a partir de um sistema formal de prestação de cuidados em saúde.

Para ocorrer o cuidado domiciliar, na realidade brasileira, é preciso a presença do cuidador porque uma parcela ínfima da população pode arcar com os custos financeiros de cuidados de enfermagem privados, muitas vezes doze, 24 horas por dia, durante semanas, meses e, às vezes, até anos, dependendo do quadro clínico do familiar adoentado. Portanto, sem a presença do cuidador, não há o cuidado domiciliar.

Há um grave erro em excluir cuidadores informais do cuidado domiciliar, o que representa uma visão política limitada das organizações de enfermagem. M esmo nos países mais ricos, cerca de $90 \%$ da assistência de home care são realizadas por cuidadores informais 5 .

O M inistério da Saúde ${ }^{6}$ define cuidador como a pessoa que mais diretamente presta cuidados, de maneira contínua e regular, podendo ou não, ser alguém da família. Suasatribuições devem ser pactuadas entre indivíduo, família, equipe e cuidador, democratizando saberes, poderes e responsabilidades. 0 cuidador "éo grandedepositário das 
orientações da equipe de profissionais responsável pelo doente", éo individuo que assume o cuidado do familiar adoentado erepresenta o elo de ligação entre doente, família e equipe de profissionais de saúde 7 . Considero que o cuidador, principalmente o familiar, é o braço direito da enfermeira, mas ao mesmo tempo também é seu "calcanhar de Aquiles".

Um bom treinamento é essencial ao cuidador, mas para assegurar que este trabalho seja eficaz e de qualidade para o doente, a equipe que o treinou deve supervisioná-lo rotinei ramente e também pela evolução do estado do paciente é possível verificar a efetividade do cuidado realizado, embora não se descarte a possi bilidade de os profissionais de enfermagem estarem envolvidos diretamente no dia a dia do doente? ${ }^{7}$. Esta forma de cuidado profissional da enfermeira diminui as oportunidades de criação de proble mas éticos e legais de exercício da profissão.

Assim, uma pergunta crucial é posta: como tem sido, por parte da enfermeira, a orientação, o ensino e a postura de advogada dos indivíduos efamiliares? Que tipo de cuidado tem compartiIhado? 0 paciente e sua família estão sendo tratados com direito à cidadania ou há uma tutela dos profissionais de saúde e da rede de assistência à saúde numa perspectiva assistencial? Ou há um discurso que prega esta autonomia e na realidadeo quese vêéum descuido eaténegligência?

É preciso refletir sobre este estado de falta de assistência. Será que isso é por livre escolha dos profissionais ou as estruturas institucionais do serviço público de saúde pouco têm organizado o sistema para fazer ao cuidado no domicílio?

No desenvolvimento do sistema de saúde no nosso país, o M inistério da Saúde, na década de noventa, instituiu o Programa de Saúde da Família (PSF); neste momento histórico, também começou a alinhavar uma possibilidade de atenção domiciliar à saúde. 0 questionamento que sempre faço é: porque não foi implementado? Ao longo de mais de dez anos, sempre houve discussões e propostas preliminares para esta forma de assistência a saúde, porque não está colocada com uma estratégia dentro do sistema desaúde? Quelógica administrativa, financeirae política rege as decisões dos gestores para a escoIha de certo tipo de assistência à saúde?

Decerta maneira, acredito queépreciso pressão da sociedade organizada e dos profissionais de saúde que acreditam na necessidade do cuidado domiciliar, uma ingerência nos órgãos decisórios sobre as ações de saúde para a implantação de um programa de atenção domiciliar à saúde em toda a esfera nacional. D esta forma, os aspectos políticos, econômicos e de gestão estariam vigorando, criando possibilidades da realização do cuidado domiciliar na rede pública de saúde.

Para que o profissional de saúderealizeo cuidado domiciliar à preparação, o ter atitudes, 0 aceitar o desafio quecuidar nas residências apresenta eo querer fazer são imprescindíveis. 0 desenvolvimento do cuidado domiciliar exigequea enfermeira se disponha e prepare para cuidar. Deste modo, ela necessariamente torna-se apta a cuidar e para isto desenvolvesuas qualidade profissionais como sensibilidade e atributos tais como maturidade, educação, saber entrar nos lares, saber conversar, ser flexível, criativa, ter objetivos de cuidado, entre outros ${ }^{3}$.

0 que temos encontrado na prática de saúde nos sistemas públicos são profissionais, entre eles a enfermeira, com mínima - para não dizer nenhuma - formação específica para o trabalho com as famílias e em seus domicílios. Encontramos também realidades de profissionais que trabaIham no PSF pouco preparados para cuidar na perspectiva da saúde da família, assim como para cuidar no domicílio. Consequentemente, enfrentamos dois problemas: um na esfera da formação/qualificação para o cuidado domiciliar e, outro, o perfil e disposição dos profissionais e principalmenteenfermeirasengajadas naespecificidade queécuidar no contexto domiciliar. Estas podem ser uma das causas do descuido dos profissionais e do sistema de saúde mantendo de certo modo a subserviência dos indivíduos efamília.

O cuidado domiciliar demanda por parte da equipe de saúde, assim como da enfermeira, elemento-chave nesta forma de assistência à saúde, o relacionamento profissional. A enfermeirarelaciona-sedeforma interpessoal, englobando a equipe, o indivíduo ea família ${ }^{8}$. Esterelacionamento é particularmente um dos maiores desafios no sistema de saúde, pois é no seu desenvolvimento que se constrói a possibilidade de autonomia ou a sujeição e depen dência dos indivíduos efamiliares com relação aos cuidados de sua saúde.

Na prática, o usuário tem dificuldades em julgar suas reais necessidades e direitos e muitas vezes pela relação de poder dos profissionais e do sistema de saúde sobre os conhecimentos das questões de saúde-doença e sobre os aspectos materiais e de organização do sistema de saúde. Estas situações acarretam, muitas vezes, a uma parcela significativa da população, um temor em expor a situação de dependência edesubserviência, porque acredita numa retaliação dos profissionais no aspecto da própria estrutura do siste- 
ma de prestação de cuidados em saúde. Assim, 0 que se vêna prática, são poucas reclamações dos usuários sobreseus direitos, consolidando a questão da necessidade de refletirmos sobre a construção de práticas de enfermagem visando à ampliação da concepção de cuidado que contribua para que os indivíduos se tornem aptos a produzir sua própria história em relação a saúde, sem "desresponsabilizar" o Estado.

É preciso o comprometimento ético da enfermeira, sendo advogada do paciente e tendo 0 objetivo de construir com ele e sua família a sua independência eautonomia de cuidados em saúde, minimizando o estado de sujeição dos usuários do sistema de saúde. É a possibilidade concreta desde que tenhamos o desejo, a força e a capacidade para tornar isto real na nossa prática profissional como enfermeira. 0 papel de advogada implica não somente em executar um cuidado correto ao paciente, mas também que a dignidadee direitos como ser humano do indivíduo sejam respeitados duranteo processo detrabalho, entendendo o usuário como corresponsável emuitas vezes como coprestador de cuida- dos numa construção solidária entre sujeitos, comunidade e Estado-nação.

O cuidado domiciliar podeestabelecer a tutela - proteção, amparo e defesa - ou dependência, sujeição vexatória, obediência, subordinação ou submissão. A capacitação para a autonomia do indivíduo e sua família demanda um serviço público desaúdesistematizado com acompanhamento, com supervisão, com estabelecimento de um tempo para a realização do cuidado no contexto domiciliar etambém com objetivos definidos desta forma de cuidados de saúde. É preciso delegar à família e ao cuidador o cuidado, mas para isto é necessário quenum primeiro momento esta família seja instrumentalizada a cuidar e que haja cuidados especiais por parte dos profissionais de saúdee depoiso ensino do cuidado ao indivíduo. $\mathrm{Ne}$ cessário sefaz verificar as condições do indivíduo e sua família em assumir este cuidado, sob o devido acompanhamento dos profissionais de saúde e muito especialmenteda enfermeira. É preciso delegar à família o seu real papel, a retomada deprovedoradecuidados desua prole, contribuindo socialmente para uma vida plena de direitos de saúde. 


\section{Referências}

1. Lacerda MR. A prática profissional de enfermagem nos aspectos sociais e políticos. Editorial. Cogitare enferm. 2006; 11(1):1-2.

2. Rice R. Home care nursing practice - concepts and application. $3^{\text {rd }}$ ed. St. Louis: M osby; 2001.

3. Lacerda MR. Tornando-se profissional no contexto domiciliar - vivencia do cuidado da enfermeira [tese]. Florianópolis (SC): Programa de Pós-Graduação em Enfermagem, Universidade Federal de Santa Catarina; 2000.

4. Klok AD, Heck RM, Casarin ST. Cuidado domiciliar: a experiência da residência multiprofissional em saúde da família /UFPEL-M S/BID. Texto contexto Enferm. 2005; 14(2):237-245.

5. Hirsch-Field M. A prática de home care cresce em todo mundo. Notícias Hospitalares [periódico na Internet] 2002 [acessado 2006 mar 01];3(35). Disponível em: http://www.prosaude.org.br/noticias/ mar2002/pgs/

6. Brasil. M inistério da Saúde. Portaria n 2.607, de 10 de dezembro de 2004. Aprova o Plano Nacional de Saúde/PNS. Diário Oficial da União 2004; 13 dez.

7. Santos NCM . H ome care: a enfermagem no desafio do atendimento domiciliar. 1a ed. São Paulo: Iátria; 2005.

8. Lacerda MR, Oliniski SR. Familiares interagindo com a enfermeira no contexto domiciliar. Rev Gaúcha Enferm. 2005; 26(1):76-87.

Artigo apresentado em 09/03/2007

Aprovado em 14/12/2007

Versão final apresentada em 31/09/2008 